\title{
THE DETECTION AND MIDGUT INTRACELLULAR LOCATION OF RICKETTSIA SYMBIONT IN THE CAMELLIA APHID (APHIS AURANTII)
}

\author{
DENG, J. - LIU, Q. - YU, Y. H. - LI, J. J. - HUANG, X. L.* \\ State Key Laboratory of Ecological Pest Control for Fujian and Taiwan Crops, \\ College of Plant Protection, Fujian Agriculture and Forestry University, Fuzhou 350002, China \\ *Corresponding author \\ e-mail: huangxl@fafu.edu.cn \\ (Received $2^{\text {nd }}$ May 2019; accepted $16^{\text {th }}$ Jul 2019)
}

\begin{abstract}
The Rickettsia, secondary symbiotic bacteria prevalent in arthropods, has been gradually recognized to play a significant role in the biology of their hosts in the past 20 years. A few previous studies have reported the occurrence of Rickettsia in several aphid species, located in the secondary bacteriocyte, sheath cell, or aphid hemolymph extracellularly. In this study, we found that Rickettsia symbiont infected camellia aphid, Aphis aurantii, with a relatively high infection rate (22\%). Moreover, based on the next-generation sequencing of 16S rRNA genes, the relative abundance of Rickettsia from an $A$. aurantii sample could even reach $59.1 \%$, which exceeded that of Buchnera, the primary endosymbiont of aphids. By using transmission electron microscopy, we also observed dense populations of rod-shaped Rickettsia symbionts in midgut epithelial cells of A. aurantii. Our study is the first to confirm that the Rickettsia can invade into midgut epithelial cells of A. aurantii, offering new insights into the location and possible infection route of Rickettsia in aphids.
\end{abstract}

Keywords: bacteria, arthropods, Next Generation Sequencing, electron microscopy, endosymbiont

\section{Introduction}

Aphids (Hemiptera, Aphididea) are considered notorious agricultural pests that cause severely damage to host plants via sucking on the phloem sap and transmitting phytopathogenic viruses (Eastop, 1977; Huang and Qiao, 2014; Skaljac, 2016). Due to the lack of various essential amino acid in the plant phloem sap, primary/obligate symbionts play an important role in providing essential nutrition to complete the diet of sap-feeding insects (Brumin et al., 2012; Hansen and Moran, 2013). For aphids, Buchnera aphidicola supplying nutrients as a primary endosymbiont has been reported in numerous studies (Baumann et al., 1995; Shigenobu et al., 2000; Wilson et al., 2010). Besides primary symbionts, insect secondary/facultative symbionts have generally been considered not necessary for host development and reproduction in the past. However, increasing evidence shows that multiple facultative symbionts might have significant influence on aphid fitness (Oliver et al., 2010), including Hamiltonella defensa for protection against parasitoids and predators (Schmid et al., 2012; Costopoulos et al., 2014), Regiella insecticola for protection against entomopathogen (ŁUkasik et al., 2013), Wolbachia for possible nutritional function (Augustinos et al., 2011). Furthermore, the endosymbiont Serratia symbiotica seems to undergo an evolutionary scenario from facultative stage to obligate stage, and establish a co-obligate endosymbiotic consortium with B. aphidicola in Cinara cedri (Lamelas et al., 2011) and Cinara tujafilina (Manzano-Marín and Latorre, 2014).

The Rickettsia are intracellular symbionts of eukaryotes and ubiquitous in arthropods (Weinert et al., 2009; Merhej and Raoult, 2011), some of which are best known as 
human and animal pathogens vectored by blood-sucking arthropods, being responsible for epidemic typhus, murine typhus or spotted fever (Raoult and Roux, 1997; Sakurai et al., 2005). Rickettsia bacteria are thought to be maternally (Weinert et al., 2009) and also plant-mediated horizontally transmitted (Caspi-Fluger et al., 2011). In general, Rickettsia bacteria are facultative symbionts in most arthropods, with influences on host fitness such as fitness benefits, female bias and sensitivity to insecticides in whitefly (Kontsedalov et al., 2008; Himler et al., 2011), male killing in ladybird beetle (Von Der Schulenburg et al., 2001), and thelytokous parthenogenesis induction in a parasitoid wasp (Hagimori et al., 2006). However, considering such wide occurrence in arthropods, more distinct and specific functions of Rickettsia symbionts await to be discovered in the vast majority of hosts.

For aphids, some studies have shown that Rickettsia can live in secondary bacteriocytes, sheath cells (Fukatsu et al., 2000; Skaljac, 2016), as well as in the hemolymph of hosts with extracellular stage (Tsuchida et al., 2005). A recent study using 454 pyrosequencing of 16S rRNA genes indicated the presence of Rickettsia in insect guts of 19 taxonomic orders (Yun et al., 2014). It seems to indicate that Rickettsia might be distributed more widely across the digestive system of insect taxa than previously thought. However, further studies are needed to investigate the real location of Rickettsia in insect digestive system, for example, free living in the gut or within the midgut epithelial cells. The camellia aphid Aphis Aurantii is a common pest species in the subtropical and tropical regions. In our study, we found that Rickettsia existed in wild A. Aurantii populations feeding on the plant Loropetalum chinense. We further investigate three questions: 1) whether the Rickettsia is common in A. aurantii populations; 2) how much can the relative abundance of Rickettsia in the symbiotic microbiome of $A$. aurantii; 3 ) whether the gut cells of $A$. aurantii contain Rickettsia symbiont.

\section{Materials and Methods}

The samples of A. aurantii were collected from seven different localities distributed in Yunnan, Guangxi, Fujian and Zhejiang provinces of southern China (Fig. 1). All samples were collected from different locations and plant individuals, making sure these samples were from different clones. All samples were directly preserved in 95\%-ethanol in the wild and frozen at $-80^{\circ} \mathrm{C}$ for further experiment in laboratory. For eliminating possible surface contaminants, all 27 individuals from 19 different clones were washed thrice in $70 \%$ ethanol, and then rinsed in sterile deionized water. DNA was isolated with DNeasy Blood \& Tissue Kit (QIAGEN) as following the manufacturer manual. The specific primer pair (Ric16SF1: 5'-TGGCTGTCGTCAGCTCGT-3' and 5'-Ric16SR1: TCCACGTCACCGTCTTGC-3') (Sakurai et al., 2005) was used to detect and classify the Rickettsia infection. All PCRs were carried out in a $50 \mu \mathrm{l}$ volume with $4 \mu \mathrm{LNA}$ template $(2-20 \mathrm{ng} / \mu \mathrm{l}), 5 \mu \mathrm{l} 10 \times$ Buffer, $2.5 \mathrm{mM}$ dNTP mixture, 10 pmol of each primer and 1 unit of ExTaq DNA polymerase (TaKaRa Bio Inc., Otsu, Japan). The PCR conditions were an initial step of $3 \mathrm{~min}$ at $95^{\circ} \mathrm{C}$ followed by 30 cycles of $30 \mathrm{~s}$ at $94^{\circ} \mathrm{C}$, $30 \mathrm{~s}$ at $52^{\circ} \mathrm{C}$ and $1 \mathrm{~min}$ at $72^{\circ} \mathrm{C}$ followed in turn by final extension of $10 \mathrm{~min}$ at $72^{\circ} \mathrm{C}$. PCR products were visualized on $1 \%$ agarose. To assure the accuracy of results, sterile deionized water was used as a negative control and some positive products (Individual ID: 17, 22 and 23) were sequenced (Table 1). 
To investigate relative abundance of Rickettsia in the symbiotic microbiome of A. aurantii, three aphid clones (HCX25 from Mangifera indica, HCX30 and HCX31 from $L$. chinense) were selected for NGS of bacterial 16S rRNA genes. Ten individuals of each clone followed the above steps of DNA extraction. The primer set (338F: 5'ACTCCTACGGGAGGCAGCA-3' and 806R: 5'-GGACTACHVGGGTWT CTAAT-3') (Srinivasan et al., 2012) was used to amplify the V3 and V4 region of the bacterial 16S rRNA genes with $95^{\circ} \mathrm{C}$ for $5 \mathrm{~min}(1$ cycle $), 95^{\circ} \mathrm{C}$ for $30 \mathrm{~s}, 50^{\circ} \mathrm{C}$ for $30 \mathrm{~s}, 72^{\circ} \mathrm{C}$ for $40 \mathrm{~s}$ ( 25 cycles), followed by $72^{\circ} \mathrm{C}$ for $7 \mathrm{~min}$. The PCR products was purified using a GeneJET Gel Extraction Kit (Thermo Fisher Scientific, Waltham, MA, United States). Finally, paired-end sequencing of the 16S rRNA was conducted on Illumina HiSeq 2500 with $2 \times 250$ bp reads (Illumina, Inc., SanDiego, CA, United States) at Biomarker Bioinformatics Technology, Co., Ltd. (Beijing, China).

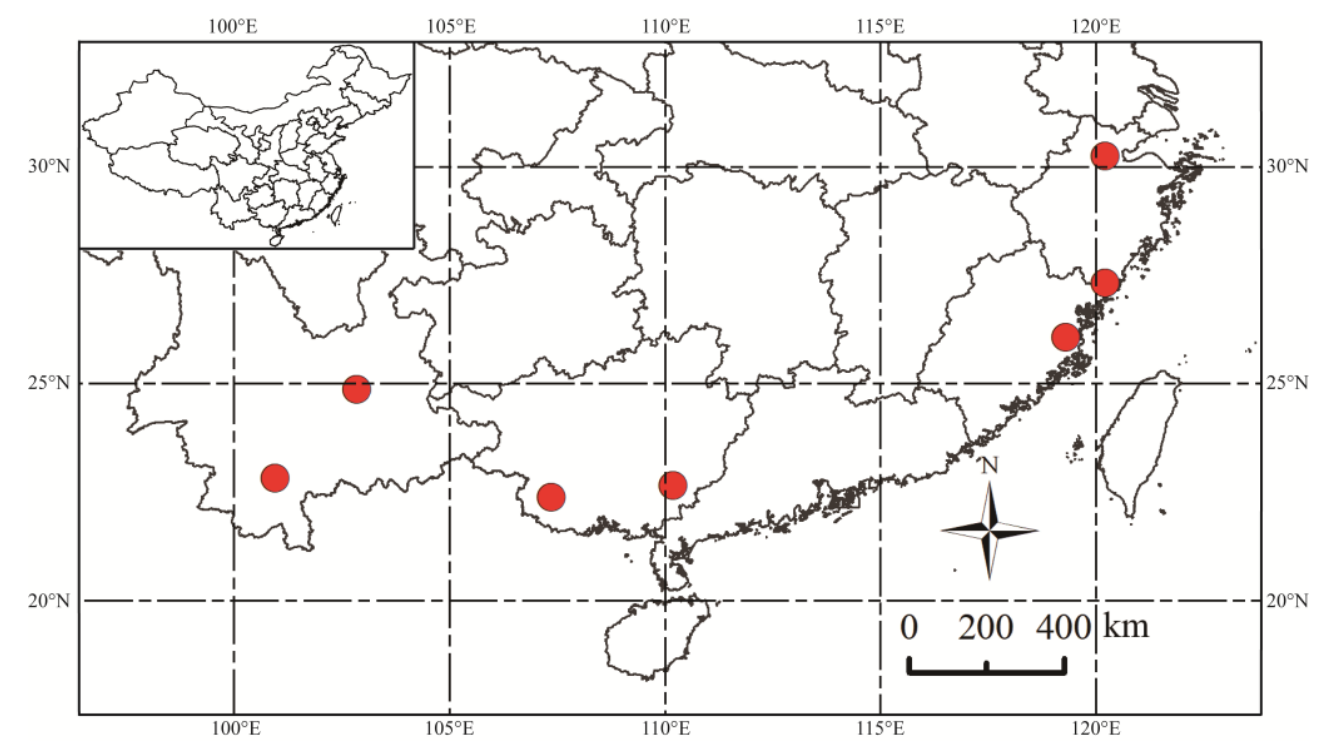

Figure 1. Overview of geographic distribution of Aphis Aurantii clones collected in this study. Collection sites are labeled with red circle

The paired-end reads were merged using FLASH v1.2.11 (Magoč and Salzberg, 2011), sequences were further quality trimmed using Trimmomatic v0.33 (Bolger et al., 2014), ensuring $>20$ quality scores on a sliding window of $50 \mathrm{bp}$. The chimera sequences were identified and removed using the UCHIME algorithm (Edgar et al., 2011). Sequences with $\geq 97 \%$ similarity were clustered into the same operational taxonomic units (OTUs) using UCLUST v10.0 (Edgar, 2010). All OTUs were identified with the RDP classifier (Version 2.2) (Wang et al., 2007) to obtain taxonomic information. The raw sequences have been submitted to the NCBI Sequence Read Archive (accession number SRR8668504, SRR8668505 and SRR8668506).

The 16S sequence of Rickettsia from HCX31 was extracted from the NGS sequences of bacterial 16S rRNA genes. The $16 \mathrm{~S}$ sequences of other Rickettsia species was selected and download from GenBank. The data was aligned using MAFFT v 7.409 (Katoh and Standley, 2013), and some sequences not in the same regions were removed using BioEdit 7.0.5 (Hall, 1999). Orientia tsutsugamushi (AF062074.1) was chosen as outgroup. Finally, maximum likelihood (ML) tree was conducted using IQTree v1.5.4 and the HKY+F+I model with 1000 ultrafast bootstraps (Nguyen et al., 2014). 
The aphid guts of HCX31 individuals were dissected in $1 \times \mathrm{PBS}$ using fine forceps. The dissected guts were prefixed in $2.5 \%$ glutaraldehyde at room temperature for $2 \mathrm{~h}$, and postfixed in $1 \%$ osmium tetroxide at room temperature for $60 \mathrm{~min}$. After dehydration through an ethanol series and acetone, the guts were embedded through an SPURR embedding medium series. Ultrathin sections were made on an ultramicrotome (EM UC7; Leica), stained with uranyl acetate and lead citrate, and observed under an $\mathrm{H}-7650$ Hitachi transmission electron microscopy at 80KV.

Table 1. The detail information of samples from our study

\begin{tabular}{|c|c|c|c|c|c|c|}
\hline Clone & SD & NGS & Individual ID & Data & Location collected & $\begin{array}{c}\text { Accession } \\
\text { number }\end{array}$ \\
\hline $\mathrm{C} 1$ & + & & 1 & $04 / 03 / 2017$ & Fuding, Fujian & \\
\hline $\mathrm{C} 2$ & + & & 2 & 08/06/2017 & Kunming, Yunnan & \\
\hline $\mathrm{C} 3$ & + & & 3 & $04 / 15 / 2017$ & Fuzhou, Fujian & \\
\hline $\mathrm{C} 4$ & + & & 4 & $10 / 16 / 2016$ & Fuzhou, Fujian & \\
\hline C5 & + & & 5 & $09 / 07 / 2015$ & Fuzhou, Fujian & \\
\hline C6 & + & & 6 & $10 / 23 / 2015$ & Fuzhou, Fujian & \\
\hline $\mathrm{C} 7(\mathrm{HCX} 30)$ & + & + & 7 & $05 / 29 / 2017$ & Fuzhou, Fujian & SRR8668504 \\
\hline $\mathrm{C} 8(\mathrm{HCX} 31)$ & $+\mathrm{R}$ & + & 8 & $09 / 22 / 2017$ & Fuzhou, Fujian & SRR8668506 \\
\hline C9 & + & & 9 & $11 / 04 / 2017$ & Fuzhou, Fujian & \\
\hline $\mathrm{C} 10$ & + & & 10 & $04 / 01 / 2018$ & Fuzhou, Fujian & \\
\hline $\mathrm{C} 11$ & + & & 11 & $09 / 24 / 2018$ & Fuzhou, Fujian & \\
\hline $\mathrm{C} 12$ & + & & 12 & $10 / 17 / 2018$ & Fuzhou, Fujian & \\
\hline $\mathrm{C} 13$ & + & & 13 & $11 / 18 / 2017$ & Pu'er, Yunnan & \\
\hline $\mathrm{C} 14$ & + & & 14 & $11 / 17 / 2017$ & Pu'er, Yunnan & \\
\hline $\mathrm{C} 14$ & $+\mathrm{R}$ & & 15 & $11 / 17 / 2017$ & Pu'er, Yunnan & \\
\hline $\mathrm{C} 15$ & + & & 16 & $11 / 01 / 2017$ & Chongzuo, Guangxi & \\
\hline $\mathrm{C} 16$ & $+\mathrm{R}$ & & 17 & $10 / 31 / 2017$ & Chongzuo, Guangxi & MK577785 \\
\hline $\mathrm{C} 16$ & $+\mathrm{R}$ & & 18 & $10 / 31 / 2017$ & Chongzuo, Guangxi & \\
\hline $\mathrm{C} 2$ & + & & 19 & 08/06/2017 & Kunming, Yunnan & \\
\hline $\mathrm{C} 2$ & + & & 20 & 08/06/2017 & Kunming, Yunnan & \\
\hline $\mathrm{C} 2$ & + & & 21 & 08/06/2017 & Kunming, Yunnan & \\
\hline $\mathrm{C} 17$ & + & & 22 & $10 / 29 / 2017$ & Yulin, Guangxi & MK577784 \\
\hline $\mathrm{C} 18$ & $+\mathrm{R}$ & & 23 & $10 / 27 / 2017$ & Yulin, Guangxi & MK577783 \\
\hline $\mathrm{C} 18$ & $+\mathrm{R}$ & & 24 & $10 / 27 / 2017$ & Yulin, Guangxi & \\
\hline C19 & + & & 25 & $06 / 17 / 2018$ & Hangzhou, Zhejiang & \\
\hline $\mathrm{C} 19$ & + & & 26 & $06 / 17 / 2018$ & Hangzhou, Zhejiang & \\
\hline C19 & + & & 27 & $06 / 17 / 2018$ & Hangzhou, Zhejiang & \\
\hline $\mathrm{C} 20(\mathrm{HCX} 25)$ & & + & & $04 / 25 / 2016$ & Fuzhou, Fujian & SRR8668505 \\
\hline
\end{tabular}

All Clones were collected from Loropetalum chinense except for C20 (HCX25) from Mangifera indica. NGS=NGS of bacterial 16S rRNA genes; SD=Specific detection using specific primers for Rickettsia. + represents using this method. $+\mathrm{R}$ represents a fragment of $300 \mathrm{bp}$ obtained from specific primers, indicating the present of Rickettsia species

\section{Results}

The Fig. 2 showed the rapid identification result of Rickettsia symbiont using the specific primers. A fragment of 300 bp was observed in 6 of 27 individuals. The result suggested a Rickettsia occurrence rate of $22.2 \%$ in our study. A total of 19 Rickettsia species with 403 bp length were selected to construct a ML phylogenetic tree. In the phylogenetic tree (Fig. 3), Rickettsia were classified into three major clades with high support values: one including Rickettsia from leeches, arthropods and our sample; a second clade including Rickettsia endosymbiont from Bemisia tabaci and some vertebrate pathogen Rickettsia such as $R$. typhi and $R$. japonica; a third clade containing sequences obtained from environmental samples. 


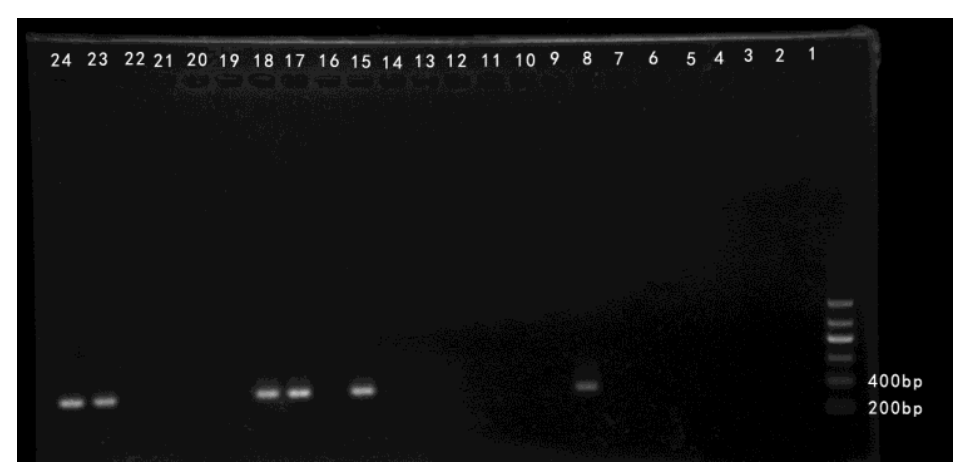

Figure 2. Specific detection of Rickettsia sp. with primers Ric16SF1 and Ric16SR1 in 19 clones and 27 individuals of A. aurantii. Lanes 1-24: 1-24 individuals, Marker: marker F (200bp $400 \mathrm{bp} 700 \mathrm{bp} 1000 \mathrm{bp} 1500 \mathrm{bp} 2000 \mathrm{bp}$ ). The remaining three are not shown due to observation in a small gel, and negative control does not show a fragment of $300 \mathrm{bp}$. The products in lanes 15, 17 and 23 have been sequenced and submitted to GenBank (Table 1)

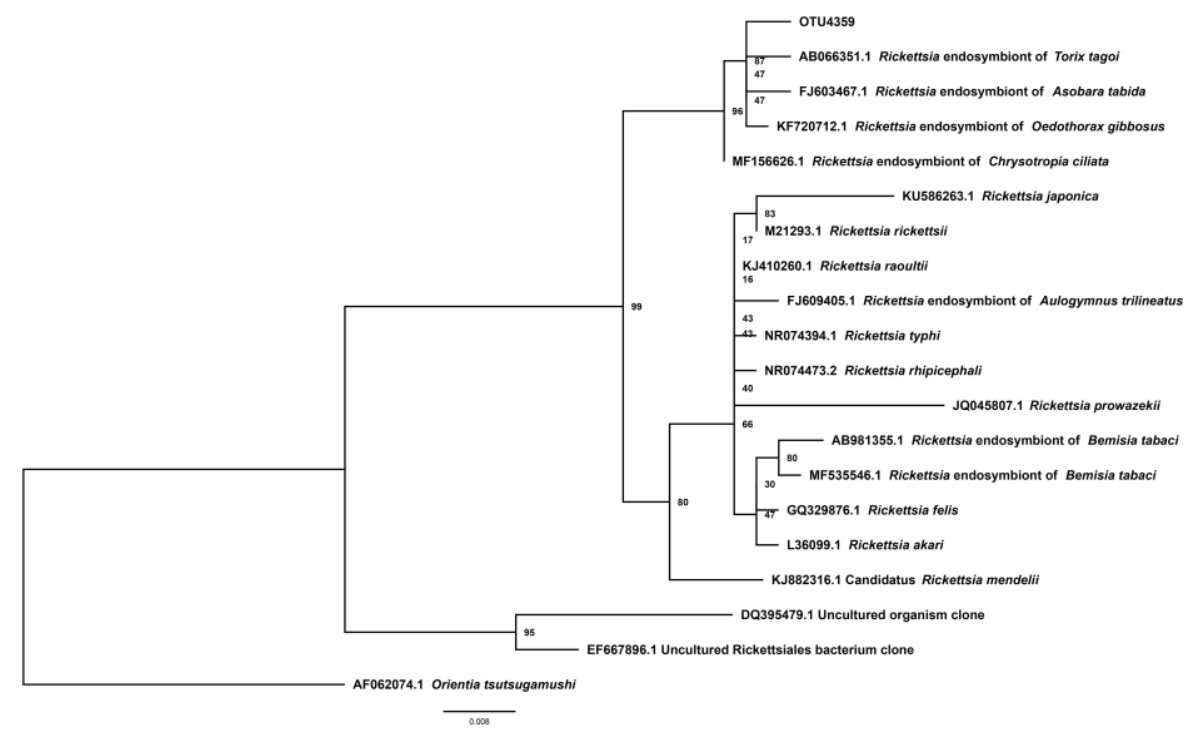

Figure 3. ML phylogenic tree of Rickettsia based on 16S rDNA sequences. OUT4359 is the sequence from our sample HCX 31. The node values represent the bootstrap values

The NGS of bacterial 16S rRNA gene yielded 47,579, 54,211 and 54,337 effective tags from HCX25, HCX30 and HCX31, respectively. The average length of effective tags was about $420 \mathrm{bp}$. The OTUs number of the rarefaction curves had very slow growth with the increase of sequencing depth, indicating that the majority of bacterial OTUs had been observed (Fig. 4A). A total of 42 OTUs were obtained at $97 \%$ sequence-similarity level (31 OTUs for HCX25; 34 OTUs for HCX30 and 34 OUTs for HCX31) (Fig. 4B). The top 10 genera based on relative abundance in three samples were illustrated in Fig. 4C. For HCX25 and HCX30, the genus of dominant bacteria was Buchnera, the primary endosymbiont of aphids, accounting for $98.3 \%$ and $98.8 \%$, respectively. For HCX31, the dominant bacteria were Rickettsia with $59.1 \%$ relative abundance, followed by Buchnera with $39.2 \%$. Electron microscopic observation of the gut of HCX31 with dense populations of rod-shaped bacteria in the gut cells (Fig. 5). The Rickettsia cells ranged from $0.35-0.5 \mu \mathrm{m}$ in width to $0.5-1 \mu \mathrm{m}$ in length. 

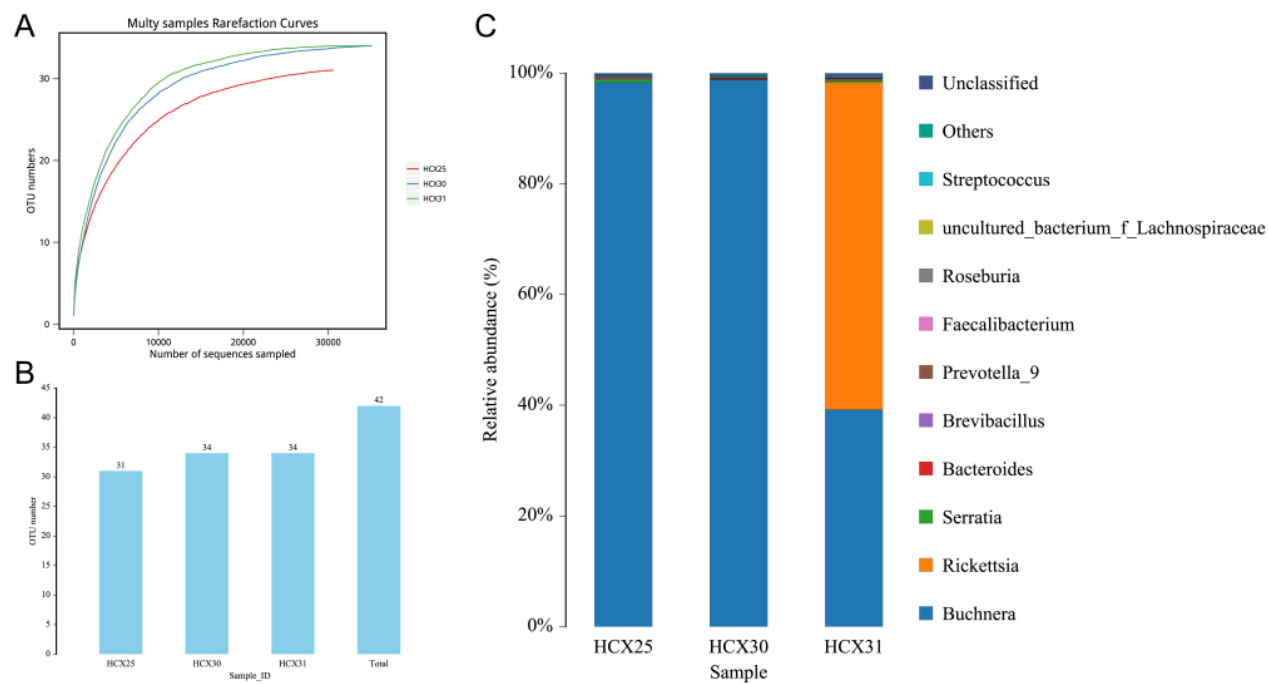

Figure 4. The NGS analysis results of bacterial 16S rRNA genes. (A) The rarefaction curves. $(B)$ The histogram of the OTUs numbers. (C) Taxonomic composition of bacteria for three A. aurantii samples

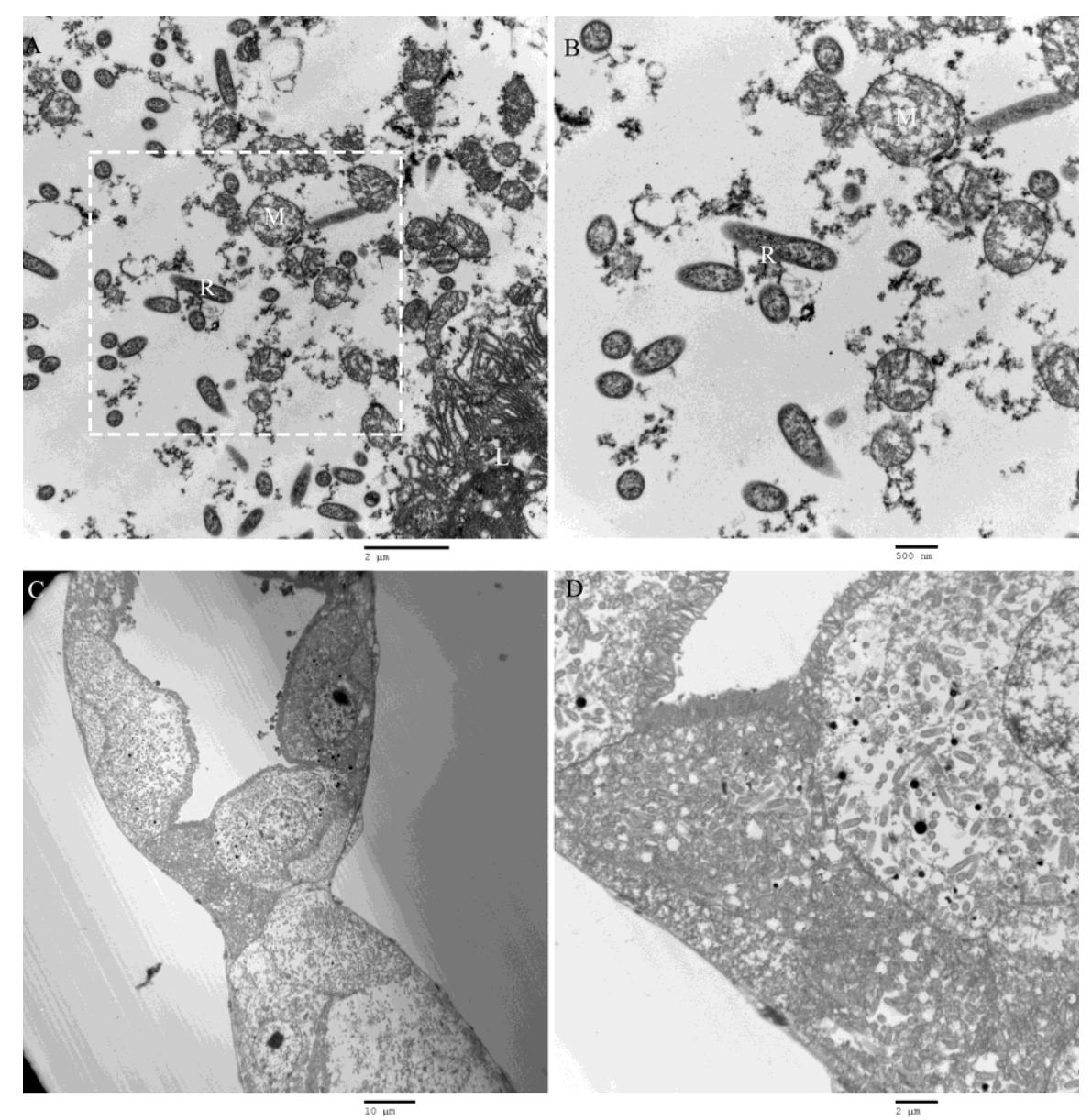

Figure 5. (A) Electron microscopic observation of the midgut epithelial cells of A. aurantii. (B) Details of the box in A. L, lumen; $M$, mitochondria; R, Rickettsia. $(C)$ and $(D)$ High density Rickettsia symbionts with rod-shape in the gut cells 


\section{Discussion}

Although all 27 individuals in our study were collected from L. chinense, the Rickettsia occurrence rate was similar with $17 \%$ of Guidolin and Cônsoli (2018) in Aphis aurantii. Cautiously, some bacteria occur at low proportion within a host, making limits of detection of specific primers due to low bacterial DNA concentration. The Rickettsia occurrence rate of $22.2 \%$ might be underestimated. Like other pathogens, some evidence have shown that the plant can be a media and provide a place for horizontal transmission of Rickettsia (Perlman et al., 2006; Caspi-Fluger et al., 2011). This may explain the phylogenetically similar symbionts occur in unrelated phytophagous insect species (Caspi-Fluger et al., 2011). The Rickettsia sequence from our sample is clustered together with Rickettsia from other arthropods in ML tree. Rickettsia are popular in many arthropod groups also including some other sap-feeders, but it is rare in aphids (Oliver et al., 2010). All records only include Acyrthosiphon pisum (Chen et al., 1996; Sakurai et al., 2005; Sepúlveda et al., 2017), Amphorophora rubi (Haynes et al., 2003), Aphis citricidus (Guidolin and Cônsoli, 2017, 2018). Haynes et al. (2003) also reported that the Rickettsia was very rarely detected in just $1 \%$ and $2 \%$ occurrence rates in natural populations of Am. rubi and Ac. pisum, respectively. A relatively high infection rate $(22 \%)$ of $A$. aurantii was reported in our study, showing a significant difference compared to Am. rubi and Ac. pisum. Interestingly, the range of host plants of $A$. aurantii is also wider with 104 plant families compared to three families of Am. rubi and 23 families of Ac. Pisum (host plant information from http://www.aphidsonwor ldsplants.info), which is concordant with the comparative result of Rickettsia infection rates among the three aphid species. Guidolin and Cônsoli (2018) also consider that the polyphagous species may tend to more frequently infected with secondary symbionts than the oligophagous one.

Little is known about the influences of Rickettsia on their aphid hosts. A few studies show that Rickettsia symbionts can enhance aphid host's resistance to natural enemies (ŁUkasik et al., 2013) and cause reductions in body weight and fecundity in the pea aphid (Chen et al., 2000). The invasive order of the most Rickettsia is considered from the gut to the haemocoel and then to the salivary glands (Perlman et al., 2006). Brumin et al. (2012) investigated the subcellular localization of Rickettsia endosymbiont in the whitefly, showing that Rickettsia infected the digestive salivary and had the possible digestive purposes. For aphids, several previous works of Rickettsia location only have shown the distribution of Rickettsia endosymbiont in secondary bacteriocytes, sheath cells and hemolymph (Fukatsu et al., 2000; Tsuchida et al., 2005; Skaljac, 2016) with the exception of the gut.

\section{Conclusion}

Our research confirms the Rickettsia location in gut cells, providing a necessary supplement to reveal a complete and clear Rickettsia localization in aphids, contributing to understanding its evolution and function in the future research. To understand Rickettsia evolution and pathogenesis, more works such as a comprehensive analysis of the entire genome need be done. Meanwhile, it will be interesting to test whether wider host plant range increases the infection possibility of Rickettsia in other aphids in the future. 
Acknowledgements. The work was supported by grants from the National Natural Science Foundation of China (Grant Numbers: 31772504, 31601860), National Key R\&D Program of China (2016YFE0203100), and Fujian Provincial Department of Science \& Technology (2015J06005). We thank Qianzhuo Mao and Haitao Wang's help for the electron microscopic observation.

\section{REFERENCES}

[1] Augustinos, A. A., Santos-Garcia, D., Dionyssopoulou, E., Moreira, M., Papapanagiotou, A., Scarvelakis, M., Doudoumis, V., Ramos, S., Aguiar, A. F., Borges, P. A. V., Manhaz, K., Latorre, A., Tsiamis, G., Bourtzis, K. (2011): Detection and characterization of Wolbachia infections in natural populations of aphids: is the hidden diversity fully unraveled? - PLoS One 6: e28695.

[2] Baumann, P., Baumann, L., Lai, C. Y., Rouhbakhsh, D., Moran, N. A., Clark, M. A. (1995): Genetics, physiology, and evolutionary relationships of the genus Buchnera: intracellular symbionts of aphids. - Review of Microbiology 49: 55-94.

[3] Bolger, A. M., Lohse, M., Usadel, B. (2014): Trimmomatic: a flexible trimmer for Illumina sequence data. - Bioinformatics 30: 2114-2120.

[4] Brumin, M., Levy, M., Ghanim, M. (2012): Transovarial transmission of Rickettsia spp. and organ-specific infection of the whitefly Bemisia tabaci. - Applied and Environmental Microbiology 78: 5565-5574.

[5] Caspi-Fluger, A., Inbar, M., Mozes-Daube, N., Katzir, N., Portnoy, V., Belausov, E., Hunter, M. S., Zchori-Fein, E. (2011): Horizontal transmission of the insect symbiont Rickettsia is plant-mediated. - Proceedings of the Royal Society B: Biological Sciences 279: 1791-1796.

[6] Chen, D. Q., Campbell, B. C., Purcell, A. H. (1996): A new Rickettsia from a herbivorous insect, the pea aphid Acyrthosiphon pisum (Harris). - Current Microbiology 33: 123-128.

[7] Chen, D. Q., Montllor, C. B., Purcell, A. H. (2000): Fitness effects of two facultative endosymbiotic bacteria on the pea aphid, Acyrthosiphon pisum, and the blue alfalfa aphid, A. kondoi. - Entomologia Experimentalis et Applicata 95: 315-323.

[8] Costopoulos, K., Kovacs, J. L., Kamins, A., Gerardo, N. M. (2014): Aphid facultative symbionts reduce survival of the predatory lady beetle Hippodamia convergens. - Bmc Ecology 14: 1-7.

[9] Eastop, V. F. (1977): Worldwide importance of aphids as virus vectors. - In Aphids As Virus Vectors Academic Press, UK.

[10] Edgar, R. C. (2010): Search and clustering orders of magnitude faster than BLAST. Bioinformatics 26: 2460-2461.

[11] Edgar, R. C., Haas, B. J., Clemente, J. C., Quince, C., Knight, R. (2011): UCHIME improves sensitivity and speed of chimera detection. - Bioinformatics 27: 2194-2200.

[12] Fukatsu, T., Nikoh, N., Kawai, R., Koga, R. (2000): The secondary endosymbiotic bacterium of the pea aphid Acyrthosiphon pisum (Insecta: Homoptera). - Applied and Environmental Microbiology 66: 2748-2758.

[13] Guidolin, A. S., Cônsoli, F. L. (2017): Symbiont diversity of Aphis (Toxoptera) citricidus (Hemiptera: Aphididae) as Influenced by host plants. - Microbial Ecology 73: 201-210.

[14] Guidolin, A. S., Cônsoli, F. L. (2018): Diversity of the most commonly reported facultative symbionts in two closely-related aphids with different host ranges. Neotropical entomology 47: 440-446.

[15] Hagimori, T., Abe, Y., Date, S., Miura, K. (2006): The first finding of a Rickettsia bacterium associated with parthenogenesis induction among insects. - Current Microbiology 52: 97-101.

[16] Hall, T. A. (1999): BioEdit: a user-friendly biological sequence alignment editor and analysis program for Windows 95/98/NT. - In Nucleic acids symposium series, Information Retrieval Ltd, London. 
[17] Hansen, A. K., Moran, N. A. (2013): The impact of microbial symbionts on host plant utilization by herbivorous insects. - Molecular Ecology 23: 1473-1496.

[18] Haynes, S., Darby, A. C., Daniell, T. J., Webster, G., Van Veen, F. J. F., Godfray, H. C. J., Prosser, J. I., Douglas, A. E. (2003): Diversity of bacteria associated with natural aphid populations. - Applied and Environmental Microbiology 69: 7216-7223.

[19] Himler, A. G., Adachi-Hagimori, T., Bergen, J. E., Kozuch, A., Kelly, S. E., Tabashnik, B. E., Chiel, E., Duckworth, V. E., Dennehy, T. J., Zchori-Fein, E. (2011): Rapid spread of a bacterial symbiont in an invasive whitefly is driven by fitness benefits and female bias. - Science 332: 254-256.

[20] Huang, X. L., Qiao, G. X. (2014): Aphids as models for ecological and evolutionary studies. - Insect Science 21: 247-250.

[21] Katoh, K., Standley, D. M. (2013): MAFFT multiple sequence alignment software version 7: improvements in performance and usability. - Molecular Biology and Evolution 30: 772-780.

[22] Kontsedalov, S., Zchori-Fein, E., Chiel, E., Gottlieb, Y., Inbar, M., Ghanim, M. (2008): The presence of Rickettsia is associated with increased susceptibility of Bemisia tabaci(Homoptera: Aleyrodidae) to insecticides. - Pest Manag Sci 64: 789-792.

[23] Lamelas, A., Gosalbes, M. J., Manzano-Marin, A., Pereto, J., Moya, A., Latorre, A. (2011): Serratia symbiotica from the aphid Cinara cedri: a missing link from facultative to obligate insect endosymbiont. - PLoS Genet 7: e1002357.

[24] ŁUkasik, P., Asch, M. V., Guo, H., Ferrari, J. J., Godfray, H. C. (2013): Unrelated facultative endosymbionts protect aphids against a fungal pathogen. - Ecology Letters 16: 214-218.

[25] Magoč, T., Salzberg, S. L. (2011): FLASH: fast length adjustment of short reads to improve genome assemblies. - Bioinformatics 27: 2957-2963.

[26] Manzano-Marín, A., Latorre, A. (2014): Settling down: the genome of Serratia symbiotica from the Aphid Cinara tujafilina zooms in on the process of accommodation to a cooperative intracellular life. - Genome Biology and Evolution 6: 1683-1698.

[27] Merhej, V., Raoult, D. (2011): Rickettsial evolution in the light of comparative genomics. - Biological Reviews 86: 379-405.

[28] Nguyen, L. T., Schmidt, H. A., von Haeseler, A., Minh, B. Q. (2014): IQ-TREE: a fast and effective stochastic algorithm for estimating maximum-likelihood phylogenies. Molecular Biology and Evolution 32: 268-274.

[29] Oliver, K. M., Degnan, P. H., Burke, G. R., Moran, N. A. (2010): Facultative symbionts in aphids and the horizontal transfer of ecologically important traits. - Annual Review of Entomology 55: 247-266.

[30] Perlman, S. J., Hunter, M. S., Zchori-Fein, E. (2006): The emerging diversity of Rickettsia. - Proceedings of the Royal Society B: Biological Sciences 273: 2097-2106.

[31] Raoult, D., Roux, V. (1997): Rickettsioses as paradigms of new or emerging infectious diseases. - Clinical Microbiology Reviews 10: 694-719.

[32] Sakurai, M., Koga, R., Tsuchida, T., Meng, X. Y., Fukatsu, T. (2005): Rickettsia symbiont in the pea aphid Acyrthosiphon pisum: novel cellular tropism, effect on host fitness, and interaction with the essential symbiont Buchnera. - Applied and Environmental Microbiology 71: 4069-4075.

[33] Schmid, M., Sieber, R., Zimmermann, Y. S., Vorburger, C. (2012): Development, specificity and sublethal effects of symbiont-conferred resistance to parasitoids in aphids. - Functional Ecology 26: 207-215.

[34] Sepúlveda, D. A., Zepeda-Paulo, F., Ramírez, C. C., Lavandero, B., Figueroa, C. C. (2017): Diversity, frequency, and geographic distribution of facultative bacterial endosymbionts in introduced aphid pests. - Insect Science 24: 511-521.

[35] Shigenobu, S., Watanabe, H., Hattori, M., Sakaki, Y., Ishikawa, H. (2000): Genome sequence of the endocellular bacterial symbiont of aphids Buchnera sp. APS. - Nature 407: 81-86. 
[36] Skaljac, M. (2016): Bacterial symbionts of aphids (Hemiptera: Aphididae). - In: Biology and Ecology of Aphids. CRC Press: Boca Raton, FL, USA.

[37] Srinivasan, S., Hoffman, N. G., Morgan, M. T., Matsen, F. A., Fiedler, T. L., Hall, R. W., Ross, F. J., McCoy, C. O., Bumgarner, R., Marrazzo, J. M. (2012): Bacterial communities in women with bacterial vaginosis: high resolution phylogenetic analyses reveal relationships of microbiota to clinical criteria. - PLoS One 7: e37818.

[38] Tsuchida, T., Koga, R., Meng, X. Y., Matsumoto, T., Fukatsu, T. (2005): Characterization of a facultative endosymbiotic bacterium of the pea aphid Acyrthosiphon pisum. - Microbial Ecology 49: 126-133.

[39] Von Der Schulenburg, J. H., Habig, M., Sloggett, J. J., Webberley, K. M., Bertrand, D., Hurst, G. D. D., Majerus, M. E. N. (2001): Incidence of male-killing Rickettsia spp. (alpha-proteobacteria) in the ten-spot ladybird beetle Adalia decempunctata L. (Coleoptera: Coccinellidae). - Applied and Environmental Microbiology 67: 270-277.

[40] Wang, Q., Garrity, G. M., Tiedje, J. M., Cole, J. R. (2007): Naive Bayesian classifier for rapid assignment of rRNA sequences into the new bacterial taxonomy. - Applied and Environmental Microbiology 73: 5261-5267.

[41] Weinert, L. A., Werren, J. H., Aebi, A., Stone, G. N., Jiggins, F. M. (2009): Evolution and diversity of Rickettsia bacteria. - BMC BIOLOGY 7: 6.

[42] Wilson, A. C. C., Ashton, P. D., Calevro, F., Charles, H., Colella, S., Febvay, G., Jander, G., Kushlan, P. F., Macdonald, S. J., Schwartz, J. F. (2010): Genomic insight into the amino acid relations of the pea aphid, Acyrthosiphon pisum, with its symbiotic bacterium Buchnera aphidicola. - Insect Molecular Biology 19: 249-258.

[43] Yun, J. H., Roh, S. W., Whon, T. W., Jung, M. J., Kim, M. S., Park, D. S., Yoon, C., Nam, Y. D., Kim, Y. J., Choi, J. H. (2014): Insect gut bacterial diversity determined by environmental habitat, diet, developmental stage, and phylogeny of host. - Applied and Environmental Microbiology 80: 5254-5264. 